\title{
Exogenous cognition and cognitive state theory: the plexus of consumer analytics and decision-making
}

\author{
Andrew Smith, John Harvey, James Goulding, Gavin Smith \& Leigh Sparks
}

Prof Andrew Smith, N/LAB, Nottingham University Business School (contact author)

Dr John Harvey, N/LAB, Nottingham University Business School

Dr James Goulding, N/LAB, Nottingham University Business School

Dr Gavin Smith, N/LAB, Nottingham University Business School

Prof Leigh Sparks, Institute for Retail Studies, University of Stirling

\begin{abstract}
We develop the concept of exogenous cognition (ExC) as a specific manifestation of an external cognitive system (ECS). Exogenous cognition describes the technological and algorithmic extension of (and annexation of) cognition in a consumption context. ExC provides a framework to enhance understanding of the impact of pervasive computing and smart technology on consumer decision-making and the behavioural impacts of consumer analytics. To this end, the paper provides commentary and structures to outline the impact of ExC and to elaborate the definition and reach of ExC. The logic of ExC culminates in a theory of cognitive states comprising of three potential decision states; endogenous cognition (EnC), symbiotic cognition (SymC) and surrogate cognition (SurC). These states are posited as transient (consumers might move between them during a purchase episode) and determined by individual propensities and situational antecedents. The paper latterly provides various potential empirical avenues and issues for consideration and debate.
\end{abstract}

Key Words: Consumer, Decision-making, Exogenous Cognition, Analytics, Marketing, Big Data, Algorithmic

\section{Acknowledgements:}

This research was supported by the EPSRC project "Neo-demographics: Opening Developing World Markets by Using Personal Data and Collaboration” EP/L021080/1

This research was supported by the EPSRC project "From Human Data to Personal Experience" EP/M02315X/1 


\section{Introduction}

Consumer decision-making often occurs via digitally mediated structures; these are increasingly data driven and oriented around analytics. Marketers are in a position to 'know' more about what customers do more than ever before. This knowledge is reliant on insights generated by algorithmic interactions between consumers and the analytics ecosystem; mining Big Data and leading to 'automated marketing' (for example see Heimbach, Kostyra and Hinz 2015; Darmody and Zwick 2020) ${ }^{1}$. Although, it should be emphasized that not all marketing is susceptible to this relentless automation, the processes and functions that are susceptible will likely deepen as we embed in the 'Internet of Things' and device-led purchase (e.g. 'intelligent' fridges ordering your food and even accounting for your propensity for variety seeking in various categories). The direction of travel is self-evident and ineluctable. In the UK in 2019 there were 50.31 million active smartphone accounts (see Statistica.com 1) in a country with a population of around 66 million (many in the possession of minors). In the US 265.9 million smart phone accounts were active in 2019 in a country with an adult population of around 252 million; $20 \%$ of that adult population had access to (lived at an address with) a smart speaker/home assistant (see Statistica.com 2). Projections suggest that this rate of penetration will continue to increase and accelerate in the US and elsewhere.

Technology has always affected consumer decision-making ${ }^{2}$ and enabled marketing but analytics driven interaction is unlike other technological impacts on marketing (see for example Dermody and Zwick 2020 - among others). Three core features (that are inextricably linked) define automated consumer marketing and the distributed system of analytics that underpins it. 1] Analytics driven marketing is temporally agile and reactive (often in near real-time) and can impact thought and behaviour in very short time frames. 2] It is individualized. Individual identifiers link people with transactional data, sentiment data, trait profiles, viewing and search biases etc. 3] It is intelligent. Artificial intelligence (AI) lies at the heart of this process of automation.

We employ the term exogenous cognition (henceforth ExC) to describe augmented/annexed cognition via smart devices and the distributed computing systems that support it. ExC provides a lens through which to examine the nexus of analytics, consumer decision-making, and the associated changes in consumer choice practices. The transformative potential of smart technology is self-evident but still requires structured thinking in terms of specific effects and outcomes (see Clayton, Leshner and Almond 2015). We draw on Smith's (2019) basic framework for categorizing the impact of consumer analytics and the brief introduction of the concept of ExC therein. We provide a number of new concepts, structures and schematics to explore the meaning and implications of ExC (culminating in a theory of cognitive states under conditions of pervasive analytics and ExC). Our aim is to provide a conceptual structure that is useful in various debates around the analytics affected consumer as well as empirical applications. To this end, we provide a conceptualization of ExC that draws on a range of pertinent thought and research in order to position it within the marketing and generic decision

\footnotetext{
${ }^{1}$ An array of algorithms and distributed systems work tirelessly to know us. Whether their inferences are accurate or not they affect our decisions nonetheless, even a wrong or poorly targeted offer will provoke a reaction. For example you might be exposed to an 'ad' for something you recently browsed on another webpage that you assessed as unsuitable. This rejection will affect your thinking and, more crucially, your failure to respond will be logged and used to refine future communications.
}

${ }^{2}$ For example, Cochoy (2008) outlines how the humble shopping cart/trolley influences consumer practice. 
theory literature. We delineate and extend the concept and this culminates in the derivation of three logical outcomes in terms of base cognitive 'states'; namely endogenous cognition (EnC), symbiotic cognition (SymC) and surrogate cognition (SurC). We call this embryonic theory cognitive state theory. This leads to a discussion of empirical applications.

\section{Context}

In terms of contextualization, Belk (2014) provides a useful counterpoint to the rationale of ExC and the exposition here (since it draws on seminal work cited in this paper, for example Clark 2008). Belk's paper is primarily concerned with notions of embodiment and identity and manifestations of self through online activity (e.g. avatars). We are concerned with the anatomy of decision-making during purchase that engages smart technology; specifically, the changes in the morphology of cognition during purchase. Belk frames the digital realm as another arena for expression and in the context he investigates this point of view is appropriate. Artefacts relating to self-conscious projections of identity (like avatars) are largely within the gift of the individual, they represent opportunities to reflect and reform notions of ideal and actual self for example (Jin 2009). The 'selves' or propensity profiles residing in the servers of the retailers, apps and ISPs that we use are not within our gift (see Turow 2012). They require our input via data streams but they create interaction, profiles and outputs (personas, offers, marketing communications, search biases, recommendations etc.) that are autonomous. These algorithmic interventions are opaque to us and outside of our immediate control. Smit, Van Noort and Voorveld (2014) Yao, Lo Re and Wang (2017) and Dolin et al. (2018) highlight the limited understanding users have of the mechanisms that underpin online advertising and MC.

Consumer and marketing research has long recognized the imperative to investigate the effects of digitization on consumer behaviour (e.g. Häubl and Trifts 2000) and the power of digital transaction data (e.g. Smith and Sparks 2004). We have already contextualized the position of this paper in relation to Belk (2014) but it is useful to determine the relationship with the wider marketing and consumer research literature. Much of the work on the digitalization of consumption has been undertaken via what might be termed sociological (including consumer culture theory) or critical perspectives on consumer research (see for example Cochoy et al. $2017)^{3}$. Some research has, like Belk, also drawn on the work on extended mind (reviewed below). For example, Jenkins and Denegri-Knott (2017) explore the knowledge, memory and imagination effects of access to online recipes and the effect on food preparation. Our scope is wider and focused on purchase and decision making generically. Moreover, we focus directly on cognitive impacts as opposed to the generalised effect on mind. Denegri-Knott, Jenkins and Lindley (2020) examine the implications for the notion of possession. Other pertinent work has examined the architecture and morphology of the digital marketing infrastructure. For example, Mellet and Beauvisage (2020) provide a valuable perspective on the building blocks and anatomy of online behavioural advertising (OBA) and automated marketing whilst Cluley

\footnotetext{
3 The relationship of this paper with digital sociology is an interesting point that requires resolution. To paraphrase Marres (2017) is digital sociology studying society or the technology? As Lupton (2014) observes digital technology is now part of what makes us a modern human. Our paper is not primarily focused on social processes (although a number of references to pertinent work are made). The principal focus here is individual decision-making and cognitive processes (therefore within the broad realms of economic psychology and more firmly located within the generic decision making research and research on consumer and purchase decision making specifically). So, our reflection of the Marres question might be posited as "are we studying consumers or consumer analytics?" We are concerned with both; ExC concerns the interface between analytics and consumer decision making and the fuzzy space in between.
} 
(2018 and 2020) provides a critique of associated marketing measures and an exposition of the implications of seeing data as a shared resource respectively (see also Wood and Ball 2013).

A number of empirical studies (like Häubl and Trifts 2000 and Brill, Munoz and Miller 2019) deal with antecedents and outcomes for specific contexts. We aim to address a fundamental change in the enactment of cognition (acknowledged outside of consumer research - e.g. Barr et al. 2015; Frischmann and Selinger 2018) in terms of any purchase in which smart technology and the associated system of consumer analytics that underpins it is a significant factor. In order to do this, we draw on insights from marketing, cognitive psychology, economics, decision theory, human-computer interaction (HCI) and theory of mind. In terms of the breadth and depth of our aims, we are more aligned with the scope of the Belk (2014) paper as opposed to Mulcahy et al. (2019). The latter paper explores the factors affecting adoption of smart technology rather than the fundamental changes in thinking and practice that the said technology instigates. Brill, Munoz and Miller (2019) provide another example of the focus on a specific technology/artefact (smart speakers/assistants) and a specified stage of consumption employing tested extant constructs (disconfirmation/satisfaction in this case). We draw on the pertinent insights from this and similar work but widen our gaze in order to provide a conceptual structure that can inform conversations on theory and empirical applications regarding the essential nature of consumer-smart technology interaction. ${ }^{4}$

\section{Exogenous cognition}

We are living through a fundamental change in the essential nature of human cognition; consumers increasingly cede decision-making responsibilities to digital services that can augment human capabilities (see Frischmann and Selinger 2018). Consumer analytics is fuelling the ongoing change and this foundational shift has to be reflected in how we consider consumer choice. We assert that digital automation changes the performance of human decision-making and cognitive function, as recognised by commentators outside marketing (e.g. Sparrow, Liu \& Wegner 2011) and emerging work in consumer research (e.g. Ward et al 2017; Darmody and Zwick 2020). Here we explore the effects on humans as consumers; specifically we focus on the effects of the anatomy of purchase decisions.

An external cognitive system is "... an external object that serves to accomplish a function that would otherwise be attained via the action of internal cognitive processes", Barr et al. (2015, p.473). External cognitive systems (ECSs) in marketing (informed by consumer analytics) are subsequently referred to as exogenous cognition (ExC). The ECS concept is adapted and developed beyond the one described by Barr et al (2015); here it refers directly to ECS effects in marketing and consumer lives. ExC and ECSs owe their roots to philosophical ruminations on the boundaries of cognition and the 'extended mind' (Merleau-Ponty, 1962; Polanyi, 1966; Bateson, 1973; Clark \& Chalmers 1998; Clark 2008; Menary 2010). ECSs predate smart technology. Frischmann and Selinger (2018) coin the term 'cognitive prosthetics' (p81); but smart technology is different, not like the analogue paper notebook for example, it is autonomous with its own cognitive aspect. Tools have always changed us but the tools were not cognitive in their own right. They may have passively stored or embodied our thoughts (e.g. a notebook or a cave painting). They could influence future thought and action but they were not intelligent, had no autonomy and were passively within the control of the

\footnotetext{
4 This research should not be confused with the work on 'smart consumers' (e.g. Roy et al. 2019); defined as consumers who voluntarily and competently engage in experience sharing not consumers who employ smart tech.
} 
originator/owner (in this case the consumer). Returning to the notebook example, consider the following scenario. In order to improve your diet and fitness you resolve to record your physical activity and food consumption in a dedicated diary or notebook. Now, imagine that the notebook is active. Imagine that it edits and re-orders contributions and it does this on an ongoing basis. Now imagine that the notebook can autonomously communicate with other people's notebooks and inform the other notebooks and dairies you keep in relation to your reflections on vacations and other consumption domains. Such virtual notebooks already exist (see for example the MyFitnessPal app). They allow users to define goals and form the basis for behaviour change using push notifications that tell you what to eat, when to eat, when to move etc. These self-tracking technologies (STTs) are effective as Wittkowski et al. 2020 determine. As Frischmann and Selinger (2018) observe, "We can describe this form of extended mind as techno-social thinking because the person extending his or her mind with the GPS system is calling on cognitive resources embedded in the technology of other people." p94. Feedback lies at the heart of ExC and the distributed system of analytics that makes it possible.

The schematic in Figure 1 provides an elementary visualization of the fundamental duality in ExC. In reality, the relationship and information/influence flows (depicted by the arrows) will blur when the device is in hand (given the real-time nature of human-device interaction - see for example Harwood et al. 2014 and Neuhofer, Buhalis and Ladkin 2015). Denegri-Knott and Molesworth (2010) highlight the fluid and symbiotic between 'real' and 'virtual' .Figure 3 accounts for this 'blurring' but requires more contextualization before exposition).

Figure 1: Simplified schematic of ExC

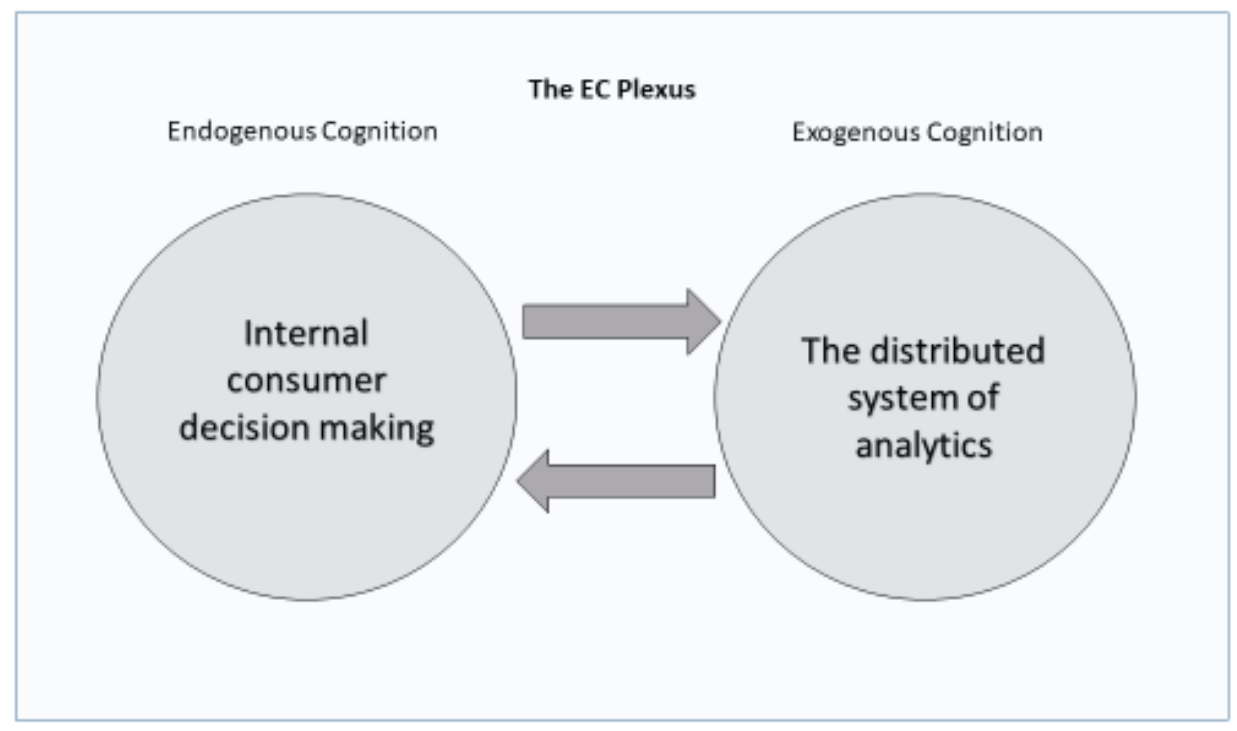

Note: Arrows are information and influence flows

We cannot do justice here to the vast literature on the philosophy of extended mind and the various controversies and standpoints therein. However, we accept as a starting premise that as people automate their decision-making through smart devices and the software applications of service providers, it is necessary to recognise that "the mental characteristics of the system are immanent, not in some part, but in the system as a whole" (Bateson, 1973, p.316). The 
concept of ExC accounts for the fact that a significant degree of our decision-making is effectively 'contracted out' to forms of computing. The nexus is the device to hand. For instance, the smart mobile device has become an indispensable device for most consumers who can afford one. Recent technological development has allowed these ECSs to become increasingly sophisticated and marketing has been a key driver for their continued development. For example, consumer analytics driven algorithms augment the information search of consumers and help to nudge behaviour across a vast range of applications; Google itself is driven by a marketing agenda; it makes money from targeting communications (so, marketing imperatives drive the architects and architecture of ExC). In effect, our minds have an external manifestation via pervasive computing technology; consumer analytics now also plays a key role in consumer decision-making (indeed in many decisions in our lives).

So, the premise is that our cognition is now extended and resides in a computational domain often driven by marketing imperatives. At this point, it is pertinent to consider the differences between human and machine computational ability and rationality within the context of generic decision theory. This is a substantive area for vigorous debate and dissonance. However, there is a broad consensus on three key differences (see Frischmann and Selinger 2018); computational ability, rationality and higher order abilities of knowing/sense. Machines are better at computation and tend to a more 'rational/logical' orientation (adhering to specified decision objectives ${ }^{5}$ ). They lack intuitive sense, and have no generalized sense of knowing (they can be trained to recognize a given product in a photo but do not necessarily 'know' what the product $i s$ ). An array of consumer and social science research also reminds us that humans serve various other objectives beyond mere rationality (e.g. symbolic interaction, hedonism etc.) but the pursuit of these other objectives often requires episodes of rational thought (e.g. ' I want to enjoy my holiday, so I will chose a destination similar to last year since I enjoyed that'). Rational choice theory and core decision theory has been assiduously critiqued and revised, but a brief review of core contributions is valuable before we return to the specific case of consumer purchase decisions. Simon's notion of bounded rationality $(1955,1990)$ still has traction; indeed it seems as relevant now as ever. It is another factor that helps to explain our willingness to rely on computational assistance for decisions since we have limits to our desire for and ability to process information. It also describes the machine's quest for a viable decision or recommendation for a consumer; the machine will make the 'best feasible decision/recommendation' (see Hillier and Lieberman 1967) without complete or perfect knowledge. Cognitive bias (Tversky and Kahneman 1986) in humans is manifested as a computational bias based on previous data/purchase. Moreover, our biases will be reflected back to us and might well be reinforced. The resulting bias or 'funnelling' of choice might result from quite elementary heuristic based algorithms. For example, a machine monitoring our use of an online retail site will operate the heuristic that repeated viewing of a product online equates to interest in that product (this is likely to inform online ad placement or nudges like individualized price reductions). Any bias here is not just endogenously cognitive but also grounded in the data (exogenous bias). The result is that repeated viewing is more likely to lead

\footnotetext{
5 This is exemplified by an example given by the school of ecological rationality (see for example Goldstein and Gigerenzer 2002 also Todd and Gigerenzer 2007 and 2012 for a flavour of work in this area). A machine tasked with catching a cricket ball will likely compute angles, trajectories, velocities etc. and derive a formula for catching the ball (it will not enjoy it or necessarily know why it is doing this). The human cricketer will not do this. The essence of ball catching comes down to keeping your eyes on the ball and moving towards the area that the ball seems to be landing. The (accomplished) human therefore achieves a high degree of success through a heuristic based on two key observations/functions (from their environment - hence ecological rationality). ExC allows a situation in which the cricketer simultaneously employs their own heuristic and deploys some technology that allows computation to augment the heuristic.
} 
to purchase if it often provokes individually targeted price reductions to induce purchase. Kahneman's (2011) 'System 1' (emotion and heuristics-driven instinctive decision-making) and 'System 2' (deliberative more rational decision-making) is still a useful way of categorizing human decisions but computational interaction can make powerful interventions to both.

Decision-making models in consumer behaviour textbooks typically present a sequence of endogenous cognitive activities that, to a greater or lesser extent, are enacted when people consume (e.g. Sethna and Blythe, 2016; East et al. 2016; Kotler et al. 2014). They remain influential as touchstones for marketing education and still serve a function as practical structures (certainly for the exposition of ExC here). They are deployed here to maximise the accessibility of the subsequent exposition and discussion of ExC (we acknowledge the alternative models and emphasize that the choice here is in the interests of exposition). Whilst helpful to explain processual decision-making, these models of cognition, exclude the decisionmaking heuristics that consumers have ceded to technological services. ExC is constituted by the automated analysis of our data, often driven by machine learning and the distributed computing system behind it. This manifests through the various selves or profiles associated with the apps, media and vendors we engage with (see Turow 2012; Carrascosa et al. 2015); illustrative examples of this relationship are depicted in simplified form in Figure 2. In practice, the infrastructure enabling ExC is fuzzy and diffuse, but many components are controlled by powerful entities such as Google, Amazon, Apple etc. Data is created, accessed and used by the consumer/user but not entirely controlled by them (Crawford, Lingel and Karppi 2015); indeed contingent control/autonomy is a function of the system of ExC with which the user interacts. The relationship is symbiotic, reflexive and reflective. 
Figure 2: Illustrative examples of the interplay between endogenous and exogenous cognition throughout the consumer decision-making process

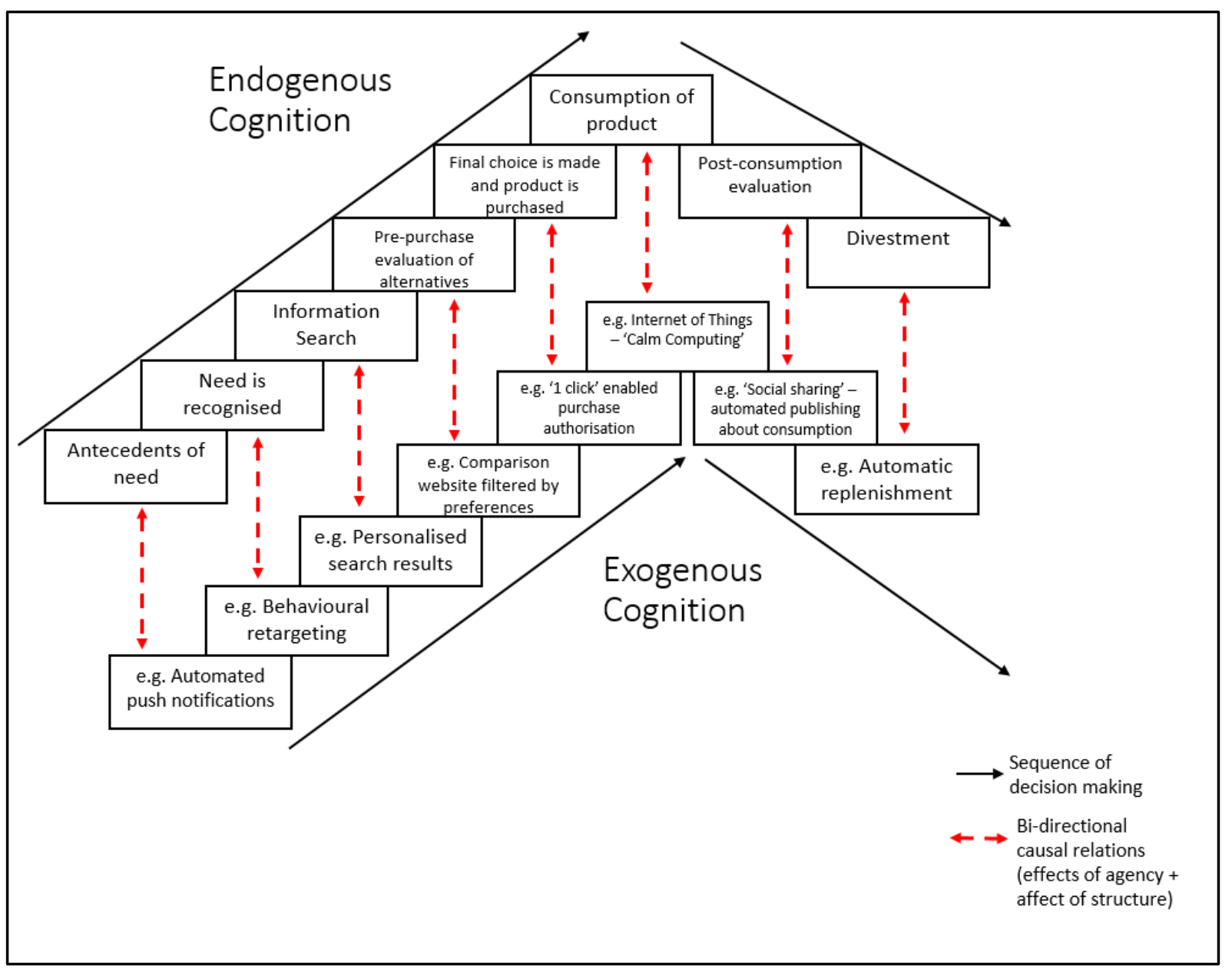

Among other things, this has morphed any 'information search' (e.g. Howard and Sheth 1969). Information search is now augmented; in fact, the information processing models are algorithmic in nature and are reflected in the process of ExC. There is still internal (retrieved information from memory) and external searching (information sought from new sources), but the external component of information searching is augmented with the intervention of ExC. The consumer will consult reviews (see Grewal and Stephen 2019), browse the web at the various stages of pre, during and post-purchase (at the extreme end some routine decisions can move towards a subscription model based on a suggestion from an online retailer). Previous searches will bias any ongoing browse prompting marketing communications based on this behaviour. Decisions are therefore effectively co-created. This extended cognition is interdependent being partially informed by the individual's life and action but residing externally and autonomously. It relies on data streams generated by the individual, but it appropriates the data to pursue its own 'thinking', and its inferences ultimately rely on the consumers own thinking and action (although it has an active influence on this internal cognition). The priorities of the marketer influence the constitution of ExC; these priorities also determine what offers or virtual shop windows we are exposed to based on the various 'selves' or profiles residing in the ExC system, for example through behavioural retargeting (e.g. Carrascosa et al., 2015). 
There is some empirical evidence that online purchase (as a proxy for the intervention of ExC) tends to induce more loyalty and less basket variety than off-line purchase for the same household (see Chu et al 2010). Much of the empirical work has been conducted on grocery shopping online and offline although the channel of actual purchase is not synonymous with ExC, ExC requires being 'online' (self-evidently). ExC can influence in-store decisions although it is more likely to 'funnel' when a list of previous purchases and preferences provides the basis for future online transactions (empirical work bears this out). For example, studies have shown that customers are less price sensitive when shopping online for groceries compared to offline trips (Degeratu, Rangaswamy \& Wu, 2000; Andrew \& Currim, 2004) a manifestation of reduced entropy ${ }^{6}$. It was also found that households switch brands less online and have a strong size choice set online than offline, i.e. much higher brand and size loyalty for customers in online grocery retail compared to in-store (Degeratu, Rangaswamy \& Wu, 2000; Andrew \& Currim, 2004). Pozzi (2012) reported in his findings that a given household systematically carry out more product exploration in-store and are more price sensitive offline than they are online, implying the same household/ customer may exhibit more inertia/lower entropy online.

Why would we surrender ourselves so readily to a smart device; giving up or augmenting our autonomy? There is ample evidence why the adoption of ExC has been so enthusiastic. The Cognitive Reflection Test (CRT) (Frederick 2005) illustrates a concept known as cognitive miserliness (e.g. Stanovich 2018). We readily opt for less burdensome forms of processing information when we can (e.g. Baron 1998; Fasolo, McClelland and Todd 2007). The reliance on this cognitive 'indolence' has never really been given its deserved prominence in marketing research; perhaps because once the point is made there is little complexity to unpack thereafter. We rely on heuristics and mental rules of thumb to get through the clutter of all the purchase decisions and other decisions in our cognitively complex lives as Tversky and Kahneman (1982) emphatically illustrated. This culminates in a 'heuristic rich' way of seeing the world and the consumption choices in it (e.g. 'French wine is best' 'German engineering is best'). Heuristics and biases are likely to be reinforced by the intervention of analytics as the algorithm reflects our sentiment, activity and behaviour back to us (see Pennycook, Cannon and Rand 2018). Confirmation bias (see Nickerson 1998 for an authoritative review) is a long established feature of human interpretation and this is likely to be reinforced by biases in algorithms as they re-reflect our biases. Perceptual and behavioural biases (heuristics, biased perception, loyalty, habit and even the propensity to variety seek) are also liable to significant reinforcement via ExC (e.g. Colleoni, Rozza and Arvidsson 2014).

At this point is it useful to summarize the features of ExC (and therefore the system of consumer analytics that underpins it):

1] Intelligent. The distributed system of consumer analytics is intelligent up to a point. It is enabled via machine learning (ML)/artificial intelligence (AI). The debates around AI and its comparability to human cognition are well worn (e.g. Searle, 2006), but the resulting consumer

\footnotetext{
${ }^{6}$ We prefer the term behavioural entropy (essentially a variance and variety measure/concept that has a 'memory' of what has gone before) after Guidotti et al's seminal 2015 application. Variety itself is a misleading term and suggests/echoes variety seeking as a stimulation driven behaviour; moreover it can lead to simple counts of basket variety that lack 'memory' or a sense of evolution (unlike entropy).
} 
analytics aspires to be intelligent and is entirely different from the analogue marketing intelligence of yesterday. It has a degree of autonomy since it is automated.

2] Individualised. Individual identifiers allow individual level profiling (Turow 2012; Carrascosa et al. 2015; Cluley and Brown 2015). There has been a blurring of advertising and direct marketing. The message is often personalised, even though it may look like a generic advert; it is individually configured and targeted (see also Tong Luo and Xu 2020). True advertising is targeted via channels and is otherwise indiscriminate. Direct to device/consumer communication is more likely to affect behaviour, particularly if it is real-time. A GPS prompted offer to your phone as you pass near your preferred muffin vendor in a town you are not familiar with is more likely to lead to purchase than a cursory glance at a billboard ad sponsored by the same vendor. Sales promotion was always powerful but it is now individually reflexive. It can respond to your recent online interest in products (see Ghose, Li and Liu 2017). In practice, the various profiles or 'selves' that inform ExC communicate, conflate and combine and overlap. Analytics-based profiling that underpins ExC is messy, dynamic and fluid.

3] Reactive and interactive. ExC depends on a process of co-creation that is covert or opaque to many consumers, so quite unlike the 'active' co-creation described by Roy et al. (2019). $\mathrm{ExC}$ is the culmination of a real-time and interactive process (as stated above it is reflexive, co-created and symbiotic). There is the obvious interaction between the person and the device/nexus. In reality the interaction is with the distributed system beyond the device - the network of servers that record an individual's behaviour and sentiment. ExC affects internal cognition and vice versa. The result is a conversant relationship and flow of interaction as depicted in Figure 1 and Figure 2. ExC is a form of emergence defined as an outcome that might not have arisen or occurred without "co-operation" or interaction (see Smith 2008 - not to be confused with Berthon, MacHulbert and Pitt's (2005) use of the term emergence - see also Taillard et al. 2016).

4] Temporally dynamic. ExC states are often updated in very short time frames. Information flows are near instantaneous, as automated decision-making progresses in parallel with endogenous cognitive states, generating new data with each interaction (Neuhofer, Buhalis and Ladkin 2015; Frischmann and Selinger 2018).

5] Diffuse and opaque to the consumer. The distributed system manifests itself in marketing communications (MC) search biases, and recommendation algorithms etc. The array of discrete and overlapping datasets and analytic structures is not readily conceivable to the consumer or user (e.g. Smit, Van Noort and Voorveld 2014; Yao, Lo Re and Wang 2017 Dolin et al. 2018). The consumer has a series of diffuse external 'selves' residing in this system but the system is only apparent when interacting with a device. The Google 'self' and the Amazon 'self' reside within a distributed system; the consumer is only aware of the results of these 'selves', or possibly some generalized knowledge of the raw data (they supply) that is used to generate further inferences about their persona.

6] Unrelenting. It is learning and unceasing; akin to an 'inductive' machine. Your online identity is independent of you to some extent and will persist after your death (e.g. Brubaker $e t$ al., 2013). The ceaseless process of 'knowing you' works as algorithms learn and improve. Even as you sleep you are providing signs of inactivity and static location (indicating you are indeed likely to be asleep). 
7] Morally cryptic. It does not actively take account of your welfare or have any innate moral sense after the design stage (Frischmann and Selinger 2018; Shank and DeSanti 2018). The human overseers can attempt to account for the ethical neutrality inherent in AI based systems by encoding ethical and welfare concerns into the system (e.g. preventing certain ads going to minors if age can be identified) or through manual oversight (e.g. removing content perceived to be inappropriate). Algorithms reflect the designer's intent, so they can be malicious. Alternatively, the data they may consume may contain 'immoral' biases. However, once unleashed they have a life of their own (web algorithms often auto-update as they self-train possibly reinforcing the biases inherent in the original design). Many automated marketing actions are largely absent of any real moral intentionality. For example, Netflix recommendations based on past viewing habits simply seek to direct content in a relatively simple and mechanistic fashion. The ethics of the tags and categories used is a more contentious point; this process of categorisation cannot avoid pervading social constructs.

\section{From exogenous cognition to emergent cognitive states}

The logic of exogenous cognition leads us to a consideration of the morphology of decisions that Figure 3 and the subsequent discussion begins. Specifically the question arises about the types or 'styles' of interaction with ExC that arises in various situations (and/or as a result of individual propensities to engage with ExC). Henceforth we refer to these types of interaction as cognitive states not styles. Decision-making 'styles' stem from a very particular area of work encompassing various facets of a decision trajectory for a given product. For example,

Eriksson, Rosenbröijer and Fagerstrøm (2017) employ the consumer styles inventory (CSI) to look at smartphone enabled purchase in the fashion sector (though not directly considering the transformation of cognition resulting from the deployment of that technology). The CSI has been around for a while (e.g. Sprotles and Kendall 1986) and has some value in relation to certain purchase scenarios, however it does not really provide a sound basis for exploring how cognitive processes are transformed in an age of ExC. Indeed, we contend that a fundamental re-appraisal of decision-making 'styles' is required under conditions of ExC. This should be based on the degree and/or intensity of ExC present within various purchase scenarios before any more complex or secondary constructs are incorporated (e.g. individual propensities and antecedents, temporal variations etc.). Figure 3 provides a typology that derives three potential forms of cognitive state under conditions of ExC and the basic interaction depicted in Figure 1 (as well as the outcomes and scenarios alluded to in Figure 2). 
Figure 3: A schematic of consumers' cognitive states under conditions of ExC

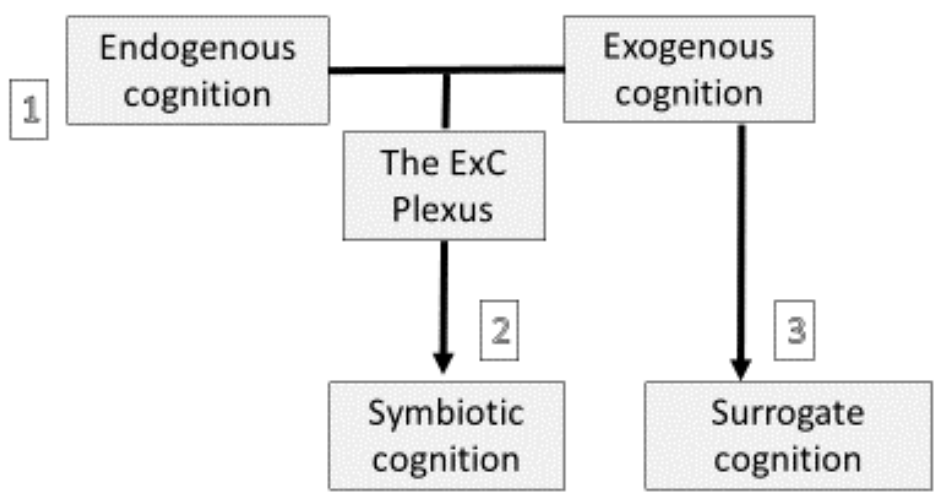

1] Purely endogenous cognition (EnC) is a possibility although, as we assert below, no decision is entirely liberated from the influence of smart technology (given that the individual makes the decision and ExC is likely embedded in their life). EnC on its own can only lead to a state of EnC if ExC does not intervene.

Pure EnC could occur for low or high involvement decisions. For example, choice of restaurant in a familiar locality for a given individual with a stable evoked set (see Wirstz and Mattila 2003) or (in terms of low involvement) a bottle of water on the way to work. Many low involvement purchases (largely driven by routine, habit or convenience - see Shah, Kumar and Kim 2014) will likely remain relatively untouched by the system supporting ExC (unless surrogate cognition occurs - see below). However, any online activity relating to such items will feedback to the consumer and could affect future purchase decisions in a manner akin to analogue marketing interventions (for example, campaign against disposable plastic bottles might provoke the consumer to a step-change in behaviour) ${ }^{7}$.

2] The inevitable outcome of the 'ExC Plexus' (Figure 1 and 3) is a form of interactive or symbiotic cognition $(\mathrm{SymC})$ in which the smart device and the user interaction essentially becomes a particular form of cognitive exercise (a 'biotechnological symbiosis' as described by Clark 2008 p93). Both EnC and ExC will nourish the other

\footnotetext{
7 A woman walks into a pub in Turin and proceeds to choose a beer. She has never been to Turin before. If she has consulted Google maps at any point during her navigation of the city or other online sources about Turin prior to departure from home then ExC has already been actively engaged. Her searches on Turin will bias what she is shown and have informed her decisions already. If she asks Google for bars nearby then she will be offered a choice set; this interaction with $\mathrm{ExC}$ will help to determine which bar she goes in. That choice will then determine the choice set for her beer.
} 
in very short time frames as a search relating to a product (for example) unfolds. The influence and action are recursive and predicated on mutual feedback. The degree to which the event or episode is symbiotic will depend on the degree to which ExC is involved. Many higher involvement purchases are likely to begin with or be contingent upon the consultation of a smartphone - or in this case smartphones - since the decision is likely to involve significant household interactions (Kirchler 1995); for example, replacement purchase of a family automobile. Searches and reviews will be used to direct offers and communications will quickly become biased by previous search histories and established preferences instantiated through filters. Figure 4 below illustrates the range of symbiotic interaction within SymC.

3] Surrogate cognition (SurC) is defined as a situation in which decision-making is 'contracted' out or sanctioned to ExC in large part or entirely (as per 'automated replenishment' in Figure 2). For example, routine purchase of a skin care product online that culminates in a recommendation for a subscription model of repeat purchase. This may require some renewal of the surrogation (e.g. subscription) every so often but the decision is essentially autonomously made or sustained in an entirely ExC state. For example, an individual might have limited expertise, time or interest in saving and investment decisions and might relinquish such decisions to an app. The day to day transfers between accounts or investments is therefore conducted by ExC. Features enabling SurC will therefore tend to be time poverty, low involvement, high habitualness, 'boring' decisions or decisions where the consumer may have limited knowledge or interest (e.g. investment and saving - see for example Gustman and Steinmeier 2001).

Many routine purchases are susceptible to conversion into subscription (e.g. Amazon often suggests subscription to a product that you seem to buy as a matter of routine/replacement). Moreover, online grocery shopping usually relies on editing a list (see Figure 4 below). This is at the extreme end of ExC's potential in many ways since the decision becomes something akin to making no more decisions (however routinized). The incidence of such purchases is likely to increase with the advance of the Internet of Things as more consumption becomes automated as a form of 'calm computing' i.e. where the interaction between the technology and its user is designed to occur in the user's periphery rather than constantly at the centre of attention (Weiser and Brown, 1997).

Temporal factors will mean that these states are not fixed and consumers will move between them during the trajectory of a purchase or decision episode. For example, they might indulge SymC during the early stages of a high involvement purchase but resort to EnC in-store. Moreover, in reality these three types way not always be entirely 'pure' and the range of SymC is variant. Figure 4 exemplifies this point in the schematic below where the ellipse area illustrates the potential variance in balance between $\mathrm{EnC}$ and $\mathrm{ExC}$ in a given episode/context. The exact location of the five text boxes relating to SymC will depend on the degree of interaction with $\mathrm{ExC}$ (the positions here are illustrative). 
Figure 4: The continuum of endogenous, symbiotic and surrogate cognition

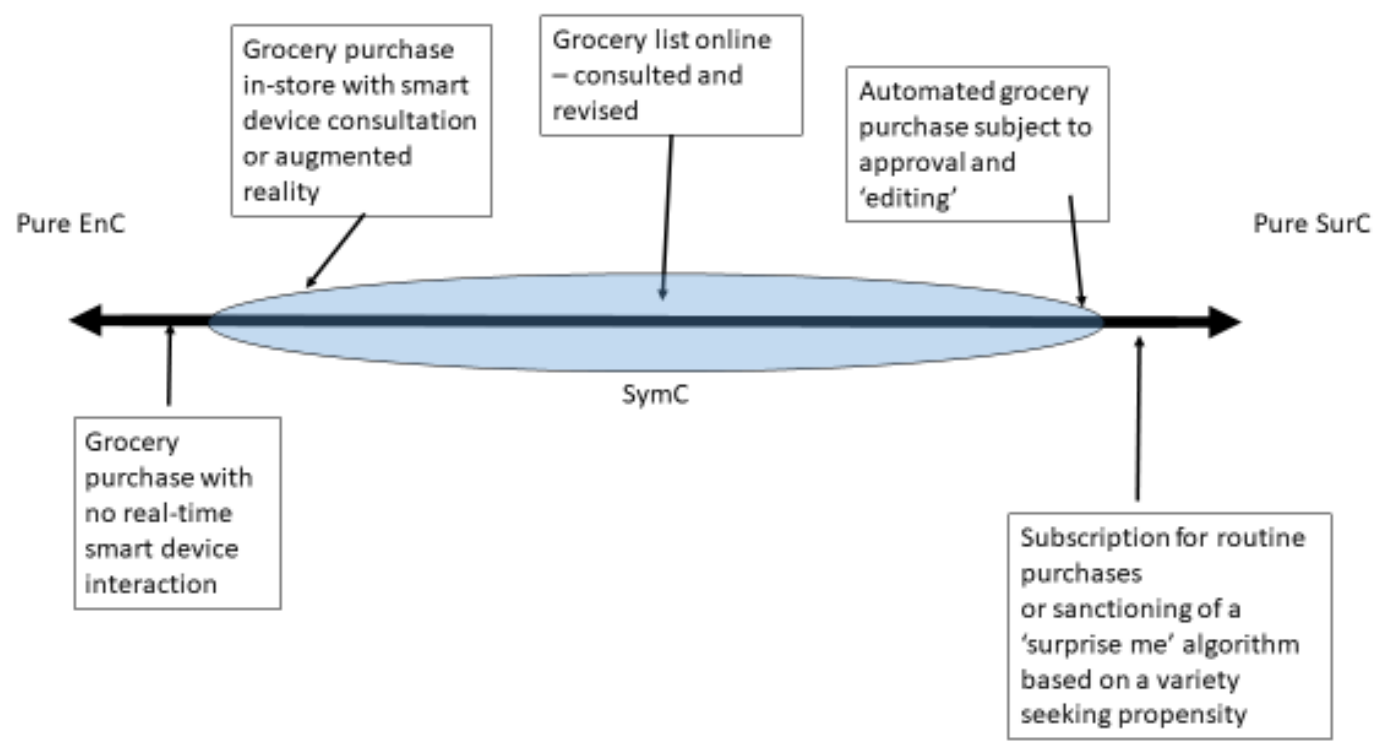

Various factors will determine whether any given purchase will be 'purely' endogenous, surrogated, or the balance between EnC and ExC in any symbiotic episode. We characterize these as either individual (propensities) or situationally determined. The potential determinants are discussed further below in the context of potential empirical applications.

\section{Theory development, corroboration and empirical deployment}

Any development will inevitably necessitate and facilitate the corroboration of the essential concept of ExC and the posited cognitive states. The structure and methods outlined here are not necessarily the only way to investigate the anatomy of ExC. We acknowledge that there may be a number of ways to interrogate the notion of cognitive states and the experience, antecedents and morphology of ExC. Indeed, a blend and range of methods is likely to be required to elaborate and affirm the concepts introduced above and we take account of that likely requirement.

The three empirical imperatives delineated below are not discrete. A sequence is suggested but the latter two stages will also contribute to the first elemental theme in terms of insight. Therefore, elements 1 to 3 are symbiotic.

\section{1] Awareness, experience and morphology}

In the first instance the consumer awareness, experience and reaction to the notion of ExC and the cognitive states outlined above requires investigation. Previous research demonstrates that awareness of the superstructure that enables ExC to exist (the system of analytics and consumer profiling) is limited (for example, Smit, Van Noort and Voorveld 2014; Yao, Lo Re and Wang 2017; Dolin et al. 2018). In light of this, and given the need for specificity, a logical starting point would be an investigation of consumer experience of variant cognitive states and 
functions during episodes of purchase and information search (when the technology enabling ExC is deployed). This initial sequence of research is outlined below.

The consumer experience of ExC and cognitive states requires depth research in the first instance, but depth research targeted at the elements of ExC not yet addressed by extant research (for example, consumer ignorance of the analytics super structure has been interrogated as stated above). Various questions remain unanswered. For example, are consumers entirely unaware of any effect on cognitive function when they purchase or search for information? Perhaps not. There might be a spectrum of awareness. Yao, Lo Re and Wang's (2017) establishment of 'folk' models of OBA (online behavioural advertising) provides a potential research design for this question. After an initial exploratory stage then consumers could be stimulated by accounts of the cognitive states depicted in Figures 3 and 4 (or adaptations and variants derived from initial research). Eslami et al. (2018) provide a protocol for exhibit driven exposure to stimulate qualitative depth research in order to surmount the issue of consumer ignorance of the process of analytics. Neuroscience methods may also have a place in mapping the cognitive morphology during variant lab based purchase tasks on different cohorts with differential use of smart technology (see Braeutigam, Lee and Senior 2019 or Wilmer et al. 2019). Mobile diaries are another possibility, Lovett and Peres 2018 examine the efficacy of this form of data capture in a consumer research context.

This blending of data streams could then be augmented with an investigation of the 'supplyside' of ExC. It could be stimulating to explore the intentions and conceptualisation inherent in analytics design (the design of ExC). How do they respond to the essential concept of ExC after exposure to exhibits and explanations and to the cognitive states exemplified in Figure 4? Do they consider the cognitive effects of their constructions?

Once the morphology and experience of variant cognitive states is better understood then the research will be in a more robust position to explore the role and function of novel (and predictable - in terms of extant research) antecedents and their relationship with behaviour.

\section{2] Antecedents and determinants}

The balance between situational and individual determinants (propensities) of cognitive states is a question that requires attention despite insights from various streams of research (e.g. knowledge levels, source credibility, cognitive effort etc.). This enquiry should attempt to identify novel antecedents not predicted by literature with 'validation' of expected antecedents $^{8}$. The HCI literature provides numerous examples of 'user' insight but the application is often generic. For example, Carr (2015) discusses automation bias and automation complacency and more generally how people respond to information presented by machines. Other key factors that would require assessment would be the degree to which an interface is consulted and variant levels of cognitive effort. The work on cognitive effort is also wide-ranging and relevant but it does not tend to focus on purchase decisions or provide for a specified application in the analytics rich/smart technology rich world we find ourselves in now. Nonetheless, work such as Garbino and Edell (1997) in consumer research and more widely in psychological applications (e.g. Piolat, Olive and Kellogg 2005; Tyler et al. 1979)

\footnotetext{
8 The likelihood that people with lower propensities for EnC effort (in given situations) will tend to indulge SymC and SurC more readily (this being related to cognitive miserliness - see Stanovich 2018) could provide the basis for a primary hypothesis for example. This could be subject to experimental methods (lab based).
} 
do provide a basis for exploring cognitive effort propensities. Luce's (1998) paper and related work is also a useful touchstone for how this stage might be executed and configured.

Other likely individual antecedents (e.g. knowledge levels) require re-investigation (given extant research into the effect of knowledge levels and other established antecedents of cognitive effort) in terms of their weight and the dynamics of their influence on whether EnC, SymC or SurC is the cognitive state outcome in a given situation. The effect of situational determinants should also be sought (e.g. the effects of syncratic vs individual choices - see Kirchler 1995). Indeed, a logical avenue might be a relatively straightforward mapping exercise of descriptive research to establish which product categories are more likely to lead to the three states. This would be suited to a survey method or possibly a scenario based experimental approach in which the various products or purchase scenarios are located on the continuum as per Figure 4 (with reference to/recording of individual and situational determinants).

The impact of behavioural traits and biases on cognitive states and vice versa could also be explored by research using transaction data (blended with other methods). There has seemingly been a preoccupation with the channel, not the form of decision-making provoked or enabled by the channel (e.g. online vs. offline - see for example Chu et al. 2010). Questions arise around the extent of and effects of ExC/SymC in terms of the reinforcement of/relationship with behavioural biases (i.e. repeat behaviour or variety seeking) in online vs. offline purchase. The cognitive impact on the effectiveness of real-time 'adaptive' sales promotion and other individualized nudges (perhaps using constructs from Devlin et al. 2007 and 2013) could also begin with analysis of transaction data (some transactional data sets record the exposure to nudges and promotions) but this would need to be augmented with a survey element and depth methods. It is possible to cross-reference transaction data with any primary data (for example via the Walgreen Boots Alliance consumer panel in the UK).

\section{3] Transitional, temporal and longitudinal dynamics}

A more challenging but equally valuable exercise would be an attempt to track how individuals move between cognitive states during the stages of a purchase episode (e.g. from pre-purchase to in-store etc.) as discussed in the preceding section (measures and indicators of these states having been derived from stages 2 and 3). These temporal effects could be addressed through an app mediated 'diary' (see Lovett and Peres 2018) or app based record approach or (less reliably) through self-reporting/recall (possibly through depth methods) or again, through neuroscience applications. A form of observational experiment is a possibility, during which a smartphone is issued to participants tasked with choosing a given high involvement product (perhaps with the limit of one week). Metrics relating to the engagement could be recorded via software-based surveillance of the decision. It would also allow assessment of and how and when the individuals used the smart tech/ExC in order to determine any commonalities or behavioural clusters. Altshuler et al. (2012) provide a comprehensive and technical analysis of the use of mobile phones as data capture devices, the work is somewhat dated now but seminal. Bogomolov et al. (2014) provide a valuable supplement and provides a useful protocol for ethical design and the derivation and use of indicator variables. Júnior et al. (2017) demonstrate how various android-based sensors can be used for sophisticated cross-referencing and inference of psychological variables and features (for example effort and attention). 


\section{Conclusion}

Exogenous cognition is a straightforward idea in its most reduced form. The central premise is that consumer cognition is often interactive and has an external manifestation and 'life'. More broadly, it reflects a need to reconceptualise how digitally-mediated consumer decisionmaking transforms the relationship between thought and action. Whilst the focus here is specifically on cognition, any adherence to the logic of ExC can inform the ongoing conversations for various other potential avenues of investigation (e.g. dependency effects, ethics, consumer sovereignty). For example, newly identified cognitive practices might enhance or compromise consumer welfare. Labrecque et al. (2013) are a typical example of the optimistic view that digital technologies enhance consumer power; Deighton and Kornfeld (2009) also see the emergent technologies as empowering (see also Sirgy and Su 2000, and Zwitter 2014). This is in stark contrast to perspectives that are more sociological in nature; for example Frischmann and Selinger (2018) see the outsourcing of decisions as increasing passivity, decreasing agency, decreasing responsibility, increasing ignorance, detachment, and decreasing independence (Darmody and Zwick 2020 give a more nuanced view).

ExC and the embryonic theory of resulting cognitive states could have an impact on decision theory in general. Marketing and consumer research contributions are sometimes under-valued in comparison to economics and cognitive psychology in terms of the inclusion into mainstream decision theory. This is odd, given that many decisions are decisions relating to purchase and transaction. The practice of marketing is at the centre of the digital transformation of human cognition and interaction. Marketing entities are designing the systems that give rise to ExC; or more accurately the architecture of ExC and the distributed system of analytics that underpins it are driven by marketing imperatives (e.g. persona construction, nudges, targeting etc.). As such, marketing and marketing theory needs to be at the heart of that debate by drawing on its own lineage of decision research and by engaging with the broader crossdisciplinary debate about decision-making and cognition in the digitally mediated era. 


\section{References}

Altshuler, Y., Aharony, N., Fire, M., Elovici, Y. and Pentland, A., 2012, September. Incremental learning with accuracy prediction of social and individual properties from mobile-phone data. In 2012 International Conference on Privacy, Security, Risk and Trust and 2012 International Confernece on Social Computing (pp. 969-974). IEEE.

Andrews, R. and Currim, I., 2004. Behavioural differences between consumers attracted to shopping online versus traditional supermarkets: implications for enterprise design and marketing strategy. International Journal of Internet Marketing and Advertising, l(1), pp. 38-61.

Baron, J., 1998. Judgment Misguided: Intuition and Error in Public Decision-making. Oxford University Press. Oxford.

Barr, N., Pennycook, G., Stolz, J.A. and Fugelsang, J.A., 2015. The brain in your pocket: Evidence that smartphones are used to supplant thinking. Computers in Human Behavior, 48, pp.473-480.

Bateson, G., 1973. Steps to an Ecology of Mind, Granada. St Albans.

Belk, R., 2014. Digital consumption and the extended self. Journal of Marketing Management, 30(11-12), pp.1101-1118.

Berthon, P., MacHulbert, J. and Pitt, L., 2005. Consuming technology: Why marketers sometimes get it wrong. California Management Review, 48(1), pp.110-128.

Bogomolov, A., Lepri, B., Ferron, M., Pianesi, F. and Pentland, A., 2014, November. Daily stress recognition from mobile phone data, weather conditions and individual traits. In Proceedings of the 22nd ACM international conference on Multimedia (pp. 477-486).

Braeutigam, S., Lee, N. and Senior, C., 2019. A role for endogenous brain states in organizational research: moving toward a dynamic view of cognitive processes. Organizational Research Methods, 22(1), pp.332-353.

Brill, T.M., Munoz, L. and Miller, R.J., 2019. Siri, Alexa, and other digital assistants: a study of customer satisfaction with artificial intelligence applications. Journal of Marketing Management, 35(15-16), pp.1401-1436.

Brubaker, J.R., Hayes, G.R. and Dourish, P., 2013. Beyond the grave: Facebook as a site for the expansion of death and mourning. The Information Society, 29(3), pp.152-163. London.

Carr, N., 2015. The Glass Cage: Where Automation is Taking Us. Random House.

Carrascosa, J.M., Mikians, J., Cuevas, R., Erramilli, V. and Laoutaris, N., 2015. I always feel like somebody's watching me: measuring online behavioural advertising. In Proceedings of the 11th ACM Conference on Emerging Networking Experiments and Technologies (p. 13). ACM. 
Chu, J., Arce-Urriza, M., Cebollada-Calvo, J. and Chintagunta, P. (2010). An Empirical analysis of shopping behavior across online and offline channels for grocery products: The moderating effects of household and product characteristics. Journal of Interactive Marketing, 24(4), pp.251-268.

Clark, A. and Chalmers, D., 1998. The extended mind. Analysis, 58(1), pp.7-19.

Clark, A., 2008. Supersizing the Mind: Embodiment, Action, and Cognitive Extension. OUP. USA.

Clayton, R.B., Leshner, G. and Almond, A., 2015. The extended iSelf: The impact of iPhone separation on cognition, emotion, and physiology. Journal of Computer-Mediated Communication, 20(2), pp.119-135.

Cluley, R. and Brown, S.D., 2015. The dividualised consumer: Sketching the new mask of the consumer. Journal of Marketing Management, 31(1-2), pp.107-122.

Cluley, R., 2018. The construction of marketing measures: The case of viewability. Marketing Theory, 18(3), pp.287-305.

Cluley, R., 2020. The politics of consumer data. Marketing Theory, 20(1), pp.45-63.

Cochoy F. 2008. Calculation, qualculation, calqulation: Shopping cart arithmetic, equipped cognition and the clustered consumer. Marketing Theory, 8 (1), pp.15-44.

Cochoy, F., Hagberg, J., McIntyre, M. P., and Sörum, N., eds. 2017. Digitalizing Consumption: How Devices Shape Consumer Culture. Routledge. London.

Colleoni, E., Rozza, A. and Arvidsson, A., 2014. Echo chamber or public sphere? Predicting political orientation and measuring political homophily in Twitter using big data. Journal of Communication, 64(2), pp.317-332.

Crawford, K., Lingel, J. and Karppi, T., 2015. Our metrics, ourselves: A hundred years of self-tracking from the weight scale to the wrist wearable device. European Journal of Cultural Studies, 18(4-5), pp.479-496.

Darmody, A. and Zwick, D., 2020. Manipulate to empower: Hyper-relevance and the contradictions of marketing in the age of surveillance capitalism. Big Data \& Society, 7(1), pp.1-12.

Degeratu, A., Rangaswamy, A. and Wu, J., 2000. Consumer choice behavior in online and traditional supermarkets: The effects of brand name, price, and other search attributes. International Journal of Research in Marketing, 17(1), pp.55-78.

Deighton, J. and Kornfeld, L., 2009. Interactivity's unanticipated consequences for marketers and marketing. Journal of Interactive Marketing, 23(1), pp.4-10.

Denegri-Knott, J. and Molesworth, M., 2010. Concepts and practices of digital virtual consumption. Consumption, Markets and Culture, 13(2), pp.109-132. 
Denegri-Knott, J., Jenkins, R. and Lindley, S., 2020. What is digital possession and how to study it: a conversation with Russell Belk, Rebecca Mardon, Giana M. Eckhardt, Varala Maraj, Will Odom, Massimo Airoldi, Alessandro Caliandro, Mike Molesworth and Alessandro Gandini. Journal of Marketing Management, pp.1-30.

Devlin , J. , Ennew , C. , McKechnie , S. and Smith , A. 2007 . A study of comparison price advertising incorporating a time- limited offer. Journal of Product and Brand Management, 16(4), pp. $280-285$.

Devlin , J. , Ennew , C. , McKechnie , S. and Smith , A. 2013 . Would you believe it? A detailed investigation of believability in comparative price advertising . Journal of Marketing Management, 29(7/ 8), pp. 793 - 811.

Dolin, C., Weinshel, B., Shan, S., Hahn, C.M., Choi, E., Mazurek, M.L. and Ur, B., 2018, April. Unpacking perceptions of data-driven inferences underlying online targeting and personalization. In Proceedings of the 2018 CHI Conference on Human Factors in Computing Systems (pp. 1-12).

East, R., Singh, J., Wright, M. and Vanhuele, M., 2016. Consumer behaviour: Applications in Marketing. Sage. London.

Eriksson, N., Rosenbröijer, C.J. and Fagerstrøm, A., 2017. The relationship between young consumers' decision-making styles and propensity to shop clothing online with a smartphone. Procedia computer science, 121, pp.519-524.

Eslami, M., Krishna Kumaran, S.R., Sandvig, C. and Karahalios, K., 2018, April. Communicating algorithmic process in online behavioral advertising. In Proceedings of the 2018 CHI Conference on Human Factors in Computing Systems (pp. 1-13).

Fasolo, B., McClelland, G.H. and Todd, P.M., 2007. Escaping the tyranny of choice: When fewer attributes make choice easier. Marketing Theory, 7(1), pp.13-26.

Frederick, S., 2005. Cognitive reflection and decision-making. Journal of Economic Perspectives, 19(4), pp.25-42.

Frischmann, B. and Selinger, E., 2018. Re-engineering Humanity. Cambridge University Press. Cambridge.

Garbarino, E.C. and Edell, J.A., 1997. Cognitive effort, affect, and choice. Journal of Consumer Research, 24(2), pp.147-158.

Ghose, A., Li, B. and Liu, S., 2017. Nudging mobile customers with real-time social dynamics. West Lafayette, IN: Purdue University.

Goldstein, D.G. and Gigerenzer, G., 2002. Models of ecological rationality: the recognition heuristic. Psychological review, 109(1), pp.75-90.

Grewal, L. and Stephen, A.T., 2019. In mobile we trust: The effects of mobile versus nonmobile reviews on consumer purchase intentions. Journal of Marketing Research, 56(5), pp.791-808. 
Guidotti, R., Coscia, M., Pedreschi, D. and Pennacchioli, D. 2015. Behavioral entropy and profitability in retail. In: 2015 IEEE International Conference on Data Science and Advanced Analytics (DSAA). IEEE, pp.1-10.

Gustman, A.L. and Steinmeier, T.L., 2001. Imperfect knowledge, retirement and saving (No. w8406). National Bureau of Economic Research.

Harwood, J., Dooley, J.J., Scott, A.J. and Joiner, R., 2014. Constantly connected-The effects of smart-devices on mental health. Computers in Human Behavior, 34, pp.267-272.

Häubl, G. and Trifts, V., 2000. Consumer decision-making in online shopping environments: The effects of interactive decision aids. Marketing Science, 19(1), pp.4-21.

Heimbach, I., Kostyra, D.S. and Hinz, O., 2015. Marketing automation. Business \& Information Systems Engineering, 57(2), pp.129-133.

Hillier, F.S. and Lieberman, G.J., 1967. Introduction to Operations Research. San Francisco: Holdenday.

Howard, J A. and Sheth, J N. 1969. The Theory of Buyer Behavior. Wiley. New Jersey.

Jenkins, R. and Denegri-Knott, J., 2017. Extending the mind: Digital devices and the transformation of consumer practices, Cochoy, F., Hagberg, J., McIntyre, M.P. and Sörum, N. (eds.), 2017. Digitalizing Consumption: How Devices Shape Consumer Culture.

Routledge. London.

Jin, S.A.A., 2009. Avatars mirroring the actual self versus projecting the ideal self: The effects of self-priming on interactivity and immersion in an exergame, Wii Fit. CyberPsychology \& Behavior, 12(6), pp.761-765.

Júnior, J.F., Carvalho, E., Ferreira, B.V., de Souza, C., Suhara, Y., Pentland, A. and Pessin, G., 2017. Driver behavior profiling: An investigation with different smartphone sensors and machine learning. PLoS one, 12(4), p.e0174959.

Kahneman, D., 2011. Thinking, Fast and Slow. Macmillan. New York.

Kirchler, E. 1995 . Studying economic decisions within private households: A critical review and design for a "couple experiences diary". Journal of Economic Psychology, 16 (3), pp. $393-419$.

Kotler P., Keller K.L., Ancarani, F., and Costabile, M., 2012 Marketing Management, 14th ed. Pearson. New York.

Labrecque, L.I., vor dem Esche, J., Mathwick, C., Novak, T.P. and Hofacker, C.F., 2013. Consumer power: Evolution in the digital age. Journal of Interactive Marketing, 27(4), pp.257-269. 
Lovett, M.J. and Peres, R., 2018. Mobile diaries-Benchmark against metered measurements: An empirical investigation. International Journal of Research in Marketing, 35(2), pp.224-241.

Luce, M.F., 1998. Choosing to avoid: Coping with negatively emotion-laden consumer decisions. Journal of Consumer Research, 24(4), pp.409-433.

Lupton, D., 2014. Digital sociology. Routledge. London.

Marres, N., 2017. Digital sociology: The reinvention of social research. John Wiley \& Sons. New Jersey.

Mellet, K. and Beauvisage, T., 2020. Cookie monsters. Anatomy of a digital market infrastructure. Consumption Markets \& Culture, 23(2), pp.110-129.

Menary, R. ed. 2010. The Extended Mind. Cambridge, MA: MIT Press.

Merleau-Ponty, M., 1962. Phenomenology of Perception. Routledge. Abingdon.

Mulcahy, R., Letheren, K., McAndrew, R., Glavas, C. and Russell-Bennett, R., 2019. Are households ready to engage with smart home technology? Journal of Marketing Management, 35(15-16), pp.1370-1400.

Neuhofer, B., Buhalis, D. and Ladkin, A., 2015. Smart technologies for personalized experiences: a case study in the hospitality domain. Electronic Markets, 25(3), pp.243-254.

Nickerson, R.S., 1998. Confirmation bias: A ubiquitous phenomenon in many guises. Review of General Psychology, 2(2), pp.175-220.

Pennycook, G., Cannon, T. D., \& Rand, D. G. (2018). Prior exposure increases perceived accuracy of fake news. Journal of Experimental Psychology: General, 147(12), $1865-1880$.

Piolat, A., Olive, T. and Kellogg, R.T., 2005. Cognitive effort during note taking. Applied Cognitive Psychology, 19(3), pp.291-312.

Polanyi, M., 1966. The tacit dimension. New York (NY): Routledge. Abingdon.

Pozzi, A., 2012. Shopping Cost and Brand Exploration in Online Grocery. American Economic Journal: Microeconomics, 4(3), pp.96-120.

Roy, S.K., Singh, G., Hope, M., Nguyen, B. and Harrigan, P., 2019. The rise of smart consumers: role of smart servicescape and smart consumer experience co-creation. Journal of Marketing Management, 35(15-16), pp.1480-1513.

Searle, J., 2006. The Chinese room argument. Encyclopaedia of cognitive science. Wiley Online.

Sethna, Z. and Blythe, J., 2016. Consumer Behaviour. Sage. London. 
Shah, D., Kumar, V. and Kim, K.H., 2014. Managing customer profits: The power of habits. Journal of Marketing Research, 51(6), pp.726-741.

Shank, D.B. and DeSanti, A., 2018. Attributions of morality and mind to artificial intelligence after real-world moral violations. Computers in Human Behavior, 86, pp.401-411.

Simon, H.A., 1955. A behavioral model of rational choice. The Quarterly Journal of Economics, 69(1), pp.99-118.

Simon, H.A., 1990. Invariants of human behavior. Annual Review of Psychology, 41(1), pp.1-20.

Sirgy, M.J. and Su, C., 2000. The ethics of consumer sovereignty in an age of high tech. Journal of Business Ethics, 28(1), pp.1-14.

Smit, E.G., Van Noort, G. and Voorveld, H.A., 2014. Understanding online behavioural advertising: User knowledge, privacy concerns and online coping behaviour in Europe. Computers in Human Behavior, 32, pp.15-22.

Smith, A. and Sparks, L., 2004. All about eve? Journal of Marketing Management, 20(3-4), pp.363-385.

Smith, A., 2019, Consumer Behaviour and Analytics. Routledge. London.

Smith, R. D., 2008. The Dynamics of Internet Traffic: Self-Similarity, SelfOrganization, and Complex Phenomena, Advances in Complex Systems, 14(6), pp.905-949.

Sparrow, B., Liu, J. and Wegner, D.M., 2011. Google effects on memory: Cognitive consequences of having information at our fingertips. Science, 333(6043), pp.776-778.

Sprotles, G.B. and Kendall, E.L., 1986. A methodology for profiling consumers' decision-making styles. Journal of Consumer Affairs, 20(2), pp.267-279.

Stanovich, K.E., 2018. Miserliness in human cognition: The interaction of detection, override and mindware. Thinking \& Reasoning, 24(4), pp.423-444.

Statistica.com 1: https://www.statista.com/statistics/553464/predicted-number-ofsmartphone-users-in-the-united-kingdom-uk/

Statistica.com 2: https://www.statista.com/statistics/201182/forecast-of-smartphoneusers-in-the-us/

Taillard, M., Peters, L.D., Pels, J. and Mele, C., 2016. The role of shared intentions in the emergence of service ecosystems. Journal of Business Research, 69(8), pp.2972-2980.

Todd, P.M. and Gigerenzer, G., 2007. Environments that make us smart: Ecological rationality. Current Directions in Psychological Science, 16(3), pp.167-171.

Todd, P.M. and Gigerenzer, G.E., 2012. Ecological Rationality: Intelligence in the World. Oxford University Press. Oxford. 
Tong, S., Luo, X. and Xu, B., 2020. Personalized mobile marketing strategies. Journal of the Academy of Marketing Science, 48(1), pp.64-78.

Turow, J. 2012. The daily you: How the new advertising industry is defining your identity and your worth. Yale University Press. New Haven, CT

Tversky, A. and Kahneman, D. 1986. Rational choice and the framing of decisions. Journal of Business, 59(4), pp. S251 - S278.

Tyler, S.W., Hertel, P.T., McCallum, M.C. and Ellis, H.C., 1979. Cognitive effort and memory. Journal of Experimental Psychology: Human Learning and Memory, 5(6), pp.607617.

Ward, A.F., Duke, K., Gneezy, A. and Bos, M.W., 2017. Brain drain: The mere presence of one's own smartphone reduces available cognitive capacity. Journal of the Association for Consumer Research, 2(2), pp.140-154.

Weiser, M., and Brown, J. S., 1997, The coming age of calm technology, in Denning, P. J. and. Metcalfe, R. M., Beyond Calculation. New York: Springer.

Wilmer, H.H., Hampton, W.H., Olino, T.M., Olson, I.R. and Chein, J.M., 2019. Wired to be connected? Links between mobile technology engagement, intertemporal preference and frontostriatal white matter connectivity. Social Cognitive and Affective Neuroscience, 14(4), pp.367-379.

Wirtz, J. and Mattila, A.S., 2003. The effects of consumer expertise on evoked set size and service loyalty. Journal of Services Marketing, 17(7), pp. 649-665.

Wittkowski, K., Klein, J.F., Falk, T., Schepers, J.J., Aspara, J. and Bergner, K.N., 2020. What gets measured gets done: Can self-tracking technologies enhance advice compliance? Journal of Service Research, p.1094670520904424.

Wood, D.M. and Ball, K., 2013. Brandscapes of control? Surveillance, marketing and the co-construction of subjectivity and space in neo-liberal capitalism. Marketing Theory, 13(1), pp.47-67.

Yao, Y., Lo Re, D. and Wang, Y., 2017, February. Folk models of online behavioral advertising. In Proceedings of the 2017 ACM Conference on Computer Supported Cooperative Work and Social Computing (pp. 1957-1969).

Zwitter, A. 2014 . Big data ethics. Big Data \& Society, 1 (2), pp. 1 - 6. 